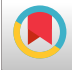

\title{
Surgical and Non-surgical Treatment Options for Piriformis Syndrome: A Literature Review
}

\author{
Neeraj Vij (D ${ }^{1,}{ }^{*}$, Hayley Kiernan ${ }^{1}$, Roy Bisht ${ }^{1}$, Ian Singleton ${ }^{1}$, Elyse M. Cornett ${ }^{2}$, Alan David Kaye ${ }^{2}$, Farnad Imani (iD ${ }^{3}$, Giustino Varrassi \\ (iD) ${ }^{4}$, Maryam Pourbahri ${ }^{3,{ }^{* *}}$, Omar Viswanath (iD ${ }^{1,2,5,6}$ and Ivan Urits (iD) ${ }^{2,7}$ \\ University of Arizona College of Medicine-Phoenix, Phoenix, USA \\ ${ }^{2}$ Department of Anesthesiology, Louisiana State University Health Shreveport, Shreveport, USA \\ ${ }^{3}$ Pain Research Center, Department of Anesthesiology and Pain Medicine, Iran University of Medical Sciences, Tehran, Iran \\ ${ }^{4}$ Paolo Procacci Foundation, Roma, Italy \\ ${ }^{5}$ Department of Anesthesiology, Creighton University School of Medicine, Omaha, USA \\ ${ }^{6}$ Valley Anesthesiology and Pain Consultants-Envision Physician Services, Phoenix, USA \\ $7^{7}$ Southcoast Health Physicians Group Pain Medicine, Wareham, USA \\ "Corresponding author: University of Arizona College of Medicine-Phoenix, Phoenix, USA. Email: neerajvij@email.arizona.edu \\ *** Corresponding author: Pain Research Center, Department of Anesthesiology and Pain Medicine, Iran University of Medical Sciences, Tehran, Iran. Email: mpourbahri1354@gmail.com
}

Received 2021 January 10; Accepted 2021 January 30.

\begin{abstract}
Context: Piriformis syndrome is a solely clinical diagnosis that often eludes the practitioner and goes underdiagnosed. PS is a pain syndrome and for those it affects, causes persistent pain and limits daily activity and work capacity. It is a form of deep gluteal syndrome that needs to be considered on the differential of low back pain as it comprises between $0.3 \%-6 \%$ of all low back pain cases and is frequently underdiagnosed. Piriformis syndrome may be primary due anatomic anomalies or secondary, though the majority of cases are secondary to some insult. The objective of this manuscript is to provide a description of the epidemiology and presentation of piriformis as well as both non-operative and operative treatment options. We review all of the recent clinical evidence regarding the aforementioned therapies.

Evidence Acquisition: Literature searches were performed using the below MeSH Terms using Mendeley version 1.19.4. Search fields were varied until further searches revealed no new articles. All articles were screened by title and abstract. Decision was made to include an article based on its relevance and the list of final articles was approved three of the authors. This included reading the entirety of the article. Any question regarding the inclusion of an article was discussed by all authors until an agreement was reached.

Results: Medical management and physical therapy show some promise; however, when conservative treatment fails minimally invasive methods such as steroid injections, botulinum toxin injections, dry needling are all efficacious and there is substantial clinical evidence regarding these therapies. In those patients in which minimally invasive techniques do not result in an adequate relief of pain and return of function, endoscopic release can be considered. Endoscopic release is far superior to open release of the piriformis syndrome given the higher success and lower rate of complications.

Conclusions: Piriformis syndrome is an important differential diagnosis in the work up of lower back pain and should not be ruled out with proper examination and testing. Clinicians should consider medical management and conservative management in the initial treatment plan for piriformis syndrome. There are many options within the conservative management and the literature shows much promise regarding these. Physical therapy, steroid injections, botulinum toxin injections, and dry needling are all potentially effective therapies with few adverse effects. Surgical options remain as gold standard, but only when conservative management has failed and the symptoms are significant to affect daily living activities. Endoscopic decompression of the sciatic nerve with or without release of the piriformis muscle has a reported high likelihood of success and a low complication rate. Current literature supports the preference of the endoscopic approach over the open approach due to improved outcomes and decreased complications. Further research is to well define the metrics for the diagnosis of piriformis syndrome and may include a need to develop diagnostic criteria.
\end{abstract}

Keywords: Piriformis Syndrome, Deep Gluteal Syndrome, Minimally Invasive, Steroid Injections, Physical Therapy, Surgical Treatment

\section{Context}

Piriformis syndrome (PS) is a somewhat vague diagnosis marked by lower back, buttock, and upper posterior thigh pain. The etiology involves the piriformis muscle compressing the sciatic nerve (1). Anytime the piriformis muscle becomes inflamed or irritated, it can affect the sciatic nerve and cause pain. Many factors can contribute to the development of piriformis syndrome such as trauma 
or anatomic anomalies. The diagnosis of PS is through clinical signs and symptoms, as agreed upon clinical criteria have yet to be determined (2). PS typically presents with low back/buttock pain that radiates inferiorly along the posterior thigh, in the distribution of the sciatic nerve (3). It is often described as a shooting, burning, or aching pain. PS is a form of deep gluteal syndrome. Deep gluteal syndrome encompasses all neurogenic posterior hip pains and also includes the proximal hamstring syndrome, the ischiofemoral impingement syndrome, and the gemelliobturator internus syndrome (4). However, PS and deep gluteal syndrome are often used synonymously. Inflammation of the intervertebral idscs, lumbar canal stenosis, and other pelvic causes are other conditions that can present similarly to PS (5).

\section{Epidemiology}

The prevalence of PS is not well known given its vague presentation and likely underdiagnosis. PS is estimated to account for $0.3 \%$ - $6 \%$ of lower back and upper/posterior thigh pain. With incidence of back/sciatic pain being roughly 40 million, there are approximately 2.4 million new cases of PS annually (3). PS typically occurs in middleaged patients, with a higher number of reported cases in females. Males typically present at an older age, whereas females typically present younger. The leading causes in males and females are compression from a tumor and anatomic variations, respectively (5).

The diagnosis of PS is a clinical diagnosis and a diagnosis of exclusion (6). There is currently no agreed-upon set of diagnostic criteria, therefore recognizing and diagnosing PS requires knowledge of the muscle's anatomy and physiologic function, as well as the relevant physical exam manevers. Patients will often present with chronic pain in the buttock and hip area which is worsened by hip movements, pain with getting up from a sitting position, and the inability to sit for extended periods of time (3). Physical exam findings include tenderness to palpation over the sciatic notch and atrophy of the gluteus maximus (7). A small elongated mass in the buttock may also be palpated on exam due to a contracted piriformis muscle (8). Several different physical exam tests can be performed to elucidate the etiology of the patient's pain such as the Beatty's test, Pace test, Freiberg test, and Lasague's sign. Electromyographic testing may also be useful in diagnosis (9). The FAIR (flexion, adduction, and internal rotation) test is an appropriate test to perform by examining the patient in the supine position while they flex the hip, move the leg towards the midline, and rotate the lower leg, with a positive test resulting in tenderness to palpation over the piriformis muscle (10).
Imaging modalities have recently become an area of study to improve the accuracy of PS diagnosis. A singlecenter retrospective study in 2019, showed the diagnostic performance of ultrasonography (US) to be significant and indicated that US may have the potential to be an alternative method for the diagnosis of PS (11). A cross-sectional study done in 2019 with 33 clinically diagnosed PS patients and 26 healthy volunteers found that US and MRI demonstrated similar muscle changes in PS patients indicating that ultrasonography may also be an important imaging modality in this condition especially when considering its cost-effectiveness (12).

\section{Risk Factors}

Primary PS accounts for fewer than $15 \%$ of cases, and include anatomic anomalies, such as the anomalous sciatic nerve path, the split sciatic nerve, or the split variant of the muscle itself (13). In the greater than $80 \%$ of the United States population, the sciatic nerve exit within the greater sciatic notch inferior to the tendon of the piriformis muscle (14). However, an anomaly in which the sciatic nerve splits into its distal components (tibial and common peroneal nerve) in the deep proximal thigh predisposes the development of sciatic nerve compression. Early branches may pass through, above, or below the piriformis muscle and become entrapped as such (15).

Causes of secondary PS include traumatic injury to the buttock or deep posterior thigh, a hypertrophic piriformis muscle in athletic individuals, sitting for prolonged periods of time, and rarely direct tumor invasion (16). A case series done in India in 2017 elucidated several common conditions associated with PS including: preceding fall, overuse injuries, lumbar spinal stenosis, fibromyalgia, a preceding fall, blunt trauma to the buttock, length length discrepancy, intramuscular gluteal injection, and use of rear pocket's wallet (5).

\section{Differential Diagnosis of Piriformis Syndrome}

Low back pain (LBP) is a common problem with a high prevalence and several different etiologies (17). In practice, it is difficult to derive a differential assessment due to the lack of definitive diagnostic criteria and broad differential, despite ongoing efforts on the topic of low back pain. A prospective observational study in 2012 found that piriformis syndrome comprised $17.2 \%$ of patients with low back pain as the presenting symptom (18).

When considering PS as a diagnosis for low back/gluteal pain, other causes of deep gluteal syndrome (DGS) must also be considered. DGS can be caused by both compression of the sciatic nerve or the pudendal 
nerve due to any pelvic lesions or anomalies that are non-discogenic. This family of syndromes includes the proximal hamstring syndrome, the ischio-femoral impingement syndrome, and the gemelli-obturator internus syndrome (4).

The differential diagnosis for low back/gluteal pain also includes hamstring injury, lumbosacral disc injuries, lumbosacral radiculopathy, lumbosacral spondylolisthesis, sacroiliac joint pathology, malignancy/tumors, and arteriovenous malformations (19).

\section{Pathophysiology}

The piriformis muscle is a pyramidal-shaped muscle with a flattened appearance that is found in deep proximal thigh posteriorly with the short external rotators of the hip. The muscle originates at the superior margin of the greater sciatic foramen and the sacrotuberous ligament, and exits the pelvis through the greater sciatic notch. It attaches on the greater trochanter of the femur (20). The piriformis muscle aids in external rotation when the hip is extended. The function of the piriformis muscle is twofold in that when the hip is in flexed, it adducts the hip. The innervation of the piriformis muscle are L5-S2 roots in the form of the sciatic nerve. The most common cause of piriformis syndrome is trauma to the buttocks which allows for the development of soft tissue inflammation, and muscle spasm, with subsequent compression of the sciatic nerve (21). As with all overuse injuries, microtrauma of the piriformis muscle can develop in walking or running long distances (22). Ultimately, overuse injuries, hypertrophy, and inflammation all lead to a sciatic nerve compression injury, and consequently the classic neuropathic pain the distribution of the sciatic nerve (23).

\section{Conservative Management}

Currently, it is recommended that patients begin with conservative treatment and then progress to invasive treatment if symptoms fail to resolve (4). In a study done by Vassalou et al. (16) 65 patients with suspected piriformis syndrome were identified. In that cohort, 42 were found to have a normal MRI or CT scan and of these 42 patients, 41 had complete resolution spontaneously or with conservative treatment by 35 days (16). Patients without significant alarm symptoms can begin by engaging in conservative management, with a relatively high success rate. Initially, short-term rest no longer than 48 hours can provide symptom relief (3). Additional measures that can be utilized before medical management focus on mobilizing the affected area. Mobilizing soft tissue restrictions and trigger points can be beneficial but should be avoided in patients that have significantly irritable symptoms (24). If motion is restricted, mobilizing the hip and lumbosacral region may also help (24).

\section{Medical Management}

Those who fail conservative management may progress to medical treatment. First-line therapy for piriformis syndrome involves non-steroidal antiinflammatory drugs (NSAIDs) such as ibuprofen $(3,16,24)$. NSAIDs alleviate the symptoms by reducing inflammation associated with repetitive motions that lead to piriformis syndrome. NSAIDs provide short-term pain relief, however, they are associated with stomach ulcer formation and this side effect should be discussed with each patient. Neuropathic agents such as gabapentin and pregabalin have also been used in patients who have not responded adequately to NSAIDs (1).

The combination of mannitol and vitamin B has also shown promising results in relieving piriformis syndrome symptoms. A 2019 study examined the utility of mannitol and vitamin B in treating piriformis syndrome. A cohort of 22 patients with piriformis syndrome was treated with a quarter of a liter of $20 \%$ infusion for the first 5 days of treatment and B vitamins (B1, B2, and B12) 6 weeks. At third and sixth-month follow-ups, there was a significant reduction in tenderness and pain during rest, at night, during activities, standing, and lying down (25).

\section{Physical Therapy}

While medical management may provide symptomatic relief, patients can also use physical therapy. Traditional stretching recommendations for those with piriformis syndrome include external rotation, hip flexion, and adduction. Gulledge, et al. (26) used CT scans to measure piriformis muscle length in 3 positions: supine, ADD stretch (external rotation of the flexed and adducted hip), and ExR stretch (adduction of the flexed and externally rotated hip) (27). The ExR and ADD stretches elongated the piriformis muscle by $12 \%$. Placing the hip joint in specific angles of hip flexion at $115^{\circ}$, external rotation at $40^{\circ}$, adduction at $25^{\circ}$ or hip flexion of $120^{\circ}$, external rotation of $50^{\circ}$, or adduction of $30^{\circ}$ produced a much larger elongation in the piriformis muscle, with results showing a 30\% - 40\% increase in muscle length (26). By using these two stretches and doing so at the specified angle, one can optimize physical therapy to produce the greatest clinical improvement. Notably, some evidence exists reading the use of pulsed radiofrequency though 
further study is needed regarding its effectiveness in piriformis syndrome (27).

Alternative therapies have been used for many nerve compression syndromes (22). Acupuncture shows some promise in piriformis syndrome. A systematic review discussing the effectiveness of acupuncture therapy on musculoskeletal disorders of the extremities referenced a randomized control trial that compared triple acupuncture to conventional acupuncture for the treatment of piriformis syndrome (28). When compared to the conventional acupuncture group, the triple acupuncture group was more likely to recover after therapy $(\mathrm{RR}=1.19, \mathrm{CI}$ : 1.04, 1.36). Another technique that has been studied on piriformis syndrome is dry needling, which differs from acupuncture in that it targets 'point' locations rather than the meridians used in acupuncture. A 2018 case series discussed three patients with piriformis syndrome who received ultrasound-guided deep needling after a poor response to oral medication (29). In each of the patients, deep needling was performed by using a convex probe and a $0.30 \times 60 \mathrm{~mm}$ needle, while targeting the piriformis and gluteus muscles.

These patients were treated for 10 days and were followed for 6 months and had complete resolution of their symptoms by the end of treatment and experienced no recurrence of pain (29). A similar set of results was seen in a 2019 randomized controlled trial by Tabatabaiee et al. (30). This trial divided 32 patients with piriformis syndrome into two study groups: one of which received three sessions of ultrasound-guided dry needling and one of which served as a control. For each patient, pain intensity was recorded at baseline, 72 hours post-treatment, and oneweek post-treatment. The group that received ultrasoundguided deep needling had a significantly lower pain rating at the one-week measurement compared to the control group. There was also a greater decrease in disability and pressure pain threshold, as well as an increased hip range of motion in the group that received dry needling (30). These studies suggest that alternative therapies such as acupuncture and deep needling can be used as effective treatment options in patients who have failed to respond to medications.

Another treatment option for piriformis syndrome is neural therapy, which is the injection of local anesthetics and can be used for painful musculoskeletal disorders. Lidocaine has been shown to be useful in the treatment of refractory chronic pain (31). In 2018, Nazlikul et al. (32) tested the efficacy of lidocaine injections as neural therapy on reducing pain and improving functionality in patients with piriformis syndrome. The 51 patients in the treatment group received six sessions of lidocaine injections and during each session were given piriformis muscle injections,
T11-S2 segmental injections, and a sacral canal injection. Patients in the control group and treatment group were also given stretching exercises. In both groups, pain levels decreased, and functionality improved, however, the changes from baseline were noticeably larger in the neural therapy treatment group. The findings in this study were statistically significant, showing that neural therapy may have a role as conjunctive therapy in patients with piriformis syndrome.

\section{Steroid Injections}

Steroid injections are saved for patients who fail to respond to conservative treatment, NSAIDS, or physical therapy $(33,34)$. While steroid injections are not universally used, recent studies have reported effectiveness in treating piriformis syndrome. In 2019, a cohort of 32 patients with piriformis syndrome was injected with $4 \mathrm{~mL}$ of lidocaine $2 \%$ and $1 \mathrm{~mL}$ of betamethasone in the piriformis muscle while using ultrasound guidance. The patients' pain was evaluated at baseline, 1-week post-injection, and 1-month post-injection. The patients showed a statistically significant improvement in all three pain scales used from baseline to one month $(\mathrm{P}<0.001)$ and in two of the three pain scales from one week to one month $(\mathrm{P}<0.001)(35)$. These findings were also seen in a 2015 study performed by Rosales et al. (36). Forty-nine patients with deep gluteal syndrome were given a mixture of $20 \mathrm{~mL}$ of saline, $4 \mathrm{~mL}$ of $2 \%$ lidocaine, and $1 \mathrm{~mL}$ of a corticosteroid (40 mg of methylprednisolone acetate) in the perisciatic region between the gluteus maximus and pelvitrochanteric muscles. Of the 49 patients, $73.7 \%$ reported some level of pain relief the average pre-injection pain score being 8.3 and the average postinjection pain score being 2.8 (36). However, $50 \%$ of patients did report recurrence of pain and on average, the treatment effect lasted 5.3 weeks, suggesting that the effect of a local anesthetic and steroid injection may eventually wear off.

While steroid injections have shown to have clinical benefit, a 2015 study found that they may not provide any additional benefit over local anesthetic injections (37). In this randomized controlled trial, one group of patients with piriformis syndrome received $5 \mathrm{~mL}$ of lidocaine $2 \%$ while the other group of patients received $4 \mathrm{~mL}$ of lidocaine $2 \%$ plus $1 \mathrm{~mL}$ of betamethasone. The authors concluded that there was no statistically significant difference in the pain level evaluated at rest and in motion during the first week, first month, and third month after the injections (37). In both groups, there was a statistically significant reduction in pain compared to baseline.

Piriformis injections can be done using a variety of methods including ultrasound, fluoroscopy, CT scan, elec- 
tromyograph, and MRI (38). Fowler et al. (39) compared the use of fluoroscopy and ultrasound in piriformis muscle injections. Between the two injection methods, there was no statistically significant difference in functional outcomes, pain scores, satisfaction, or procedure time.

A 2019 study tested the use of sciatic perineural hydrodissection prior to ultrasound-guided corticosteroid injection for treatment of piriformis syndrome (40). Hydrodissection is a minimally invasive technique in which the perineural tissue space is dissected using a fluid injection. This method works by reducing adhesions and broaden the tissue space allowing for the focalization of anesthetic and corticosteroid injections (40). In total, 38 patients were studied, with 17 given betamethasone and 21 given triamcinolone acetonide. In 32 of the 38 patients (84\%), there was immediate pain relief following injection. The average preprocedural pain rating was 4.7/10 and the average postprocedural pain rating was $0.5 / 10$ (40). A total of 19 of the 32 patients followed up after an average of 33.6 days and $9 / 19(47 \%)$ reported continuous pain relief at this point. While this study is promising, further research can be done to compare the use of hydrodissection before steroid injections to injections without any pretreatment.

\section{Botulinum Injections}

Botulinum toxin type A (BoNT-A) prevents the exocytosis of excitatory neurotransmitters the peripheral and sensory neurons by cleaving SNARE proteins and inhibiting their action (41). The dysregulation of sodium channels caused by the toxin is responsible for decreased pain transmission. In fact, anomalous sodium channels are even responsible for pain syndromes such as erythromelalgia (41). This results in inhibited release of acetylcholine at the neuromuscular junction presynaptically and thus causes paralysis of the muscle (42).

Many such factors are known to sensitize muscular nociceptors and stimulate muscle and myofascial pain, including calcitonin gene-related peptide (CGRP), substance $\mathrm{P}$, bradykinins, serotonin, potassium, and prostaglandin E2 $(43,44)$. The primary mechanism of action of BoNT-A is to inhibit the release of substance P release and other inflammatory factors $(41,43)$. Research has elucidated that BoNT-A serves to inhibit the release of substance $P$ from cultured embryonic dorsal root ganglion neurons. It also reduces release of CGRP from culture trigeminal ganglia neurons $(41,43)$. It is hypothesized that the BoNT-A injections similarly inhibit the release of these neuropeptides in vivo, as well as reduce the level of lactate in the contracted muscle of interest, which leads to an inhibited release of sensitizing mediators (43).
Proper BoNT-A injection technique is essential due to the small size and deep location of the piriformis as well as its anatomical relationship to other key neurovascular structures $(43,45)$. Ultrasound guidance is non-invasive and its successful use during BoNT-A administration in PMS is well documented in the literature $(43,46)$.

Guidance with CT, MRI, or fluoroscopy are other options for injections into the iriformis muscle injections. MRI improves targeting and success is reported when the piriformis muscle is abnormally thin or the patient is overweight. It is also helpful when a combination injection of the infrapiriformis foramen of the greater sciatic notch is being done $(42,45)$. An 100 - 200 unit injection of BoNTA, performed intramuscularly, leads to weakness and atrophy of the injected muscle and can potentially reversing any nerve compression that has occurred (42).

A recent class II, randomized, blinded, placebocontrolled clinical trials studying the efficacy of BoNT-A in piriformis syndrome by Fishman et al. (47) reported a significant improvement of pain. This study had a statistically significant reduction in visual analog scale pain scores, which is a validated, subjective measure for acute and chronic pain, as well as flexion, adduction, and internal rotation scores, which measures indicate pressure placed on the sciatic nerve by the piriformis muscle (47). Multiple recent cases reports in the literature have also documented the resolution of pain and return of function with BoNT-A injections (43, 48-50).

Adverse events documented in the literature include injection-site pain, flu-like symptoms, stiff neck, anterior thigh pain and weakness, and severe buttock pain (47). Muscle atrophy and generation of fat have been reported following botulinum toxin injection in piriformis syndrome (49). Relapse of symptoms even years after treatment has also been documented (50).

Imaging modalities allow for localization of the piriformis muscle requires which can thus help avoid nerve injury during the procedure. The cost of botulinum toxin is also higher than that of local anesthetics, which can be significant with the increasing number of units used. Ultimately, this treatment approach is relevant for those in whom the disease has progressed to cause significant difficulty in daily living activities and is refractory to first line treatments (49).

\section{Surgical Techniques}

Typically, surgical intervention is reserved for patients that have had conservative treatment fail (51). Conservative treatment failure can be considered when pain (buttock pain or sciatica) is not relieved after attempting activity modification strategies, medications, physical ther- 
apy, localized injections, and/or extracorporeal shock wave therapy $(51,52)$. Han et al. (52) reported waiting at least 3 months before considering surgical treatment. It should be kept in mind that surgical treatment does often open the door to discussion regarding opioid use and its potential for misuse $(53,54)$.

This condition is surgically managed through dissection and subsequent decompression of the sciatic nerve and can also involve piriformis musculature release. These surgeries can be performed open or endoscopically $(51,55$, 56). Sciatic nerve decompression is performed by cauterizing fibrovascular scar bands via radiofrequency probes and removing with an arthroscopic shaver or dissection scissors $(57,58)$. The tendinous portions of the piriformis may be split and the piriformis tendon may be released from its insertion on the greater trochanter using a radiofrequency hook probe and a retrograde technique (57, 59).

Open sciatic nerve decompression carries a relatively high risk of postoperative complications such as hematoma formation, infections, as well as long rehabilitation time and poor cosmetic appearance when compared with an endoscopic approach $(60,61)$. The endoscopic approach also allows for improved visualization and less soft tissue and muscle damage which could help in both decrease postoperative pain scores as well as decrease recovery times (55). Improved visualization also helps surgeons when dealing with anatomic vascular and fibrous anomalies that are responsible for the syndrome (55).

Kay et al. (51) in a review of 28 studies found the outcomes of open and endoscopic management of piriformis and other deep gluteal syndromes to be positive with a clear improvement pain at final follow-up as compared preoperative levels reported in all studies, although endoscopic had better outcomes. Ilizaliturri et al. (57) concluded in a retrospective review of fifteen patients that release of the piriformis mucle's tendon endoscopically improved function, diminished pain, allowed patients to return to daily activities without symptoms. Han et al. (52) in a retrospective review of twelve patients who underwent resection of the piriformis muscle with/without neurolysis of the sciatic nerve found that the post-operative VAS score was statistically significantly lower when compared to the pre-operative VAS.

There is generally a low incidence of complications, particularly for the endoscopic approach (51). Kay et al. (51) report 1 major ( $<1 \%$ of the sample) and 21 minor complications (8\%) for open surgical management consisting of temporary numbness or paresthesias, permanent paresthesias, hyperesthesias, superficial surgical site infection, and worsened pain. However, only 1 complication (1\%) was reported for endoscopic surgery, which was the patient having worsened pain at final follow-up (51). Scar tissue formation after both open and endoscopic approaches causing recurrence of sciatic nerve compression has also been reported $(61,62)$.

The proper indications for surgery must be met before undergoing surgical management. These include the proper diagnosis based on clinical and spine evaluations and no response to conservative treatment of at least physical therapy and one injection (52). Although a relatively simple procedure with low morbidity, as in all surgery the patient must be able to undergo anesthesia (52).

\section{Conclusions}

Piriformis Syndrome is a pain syndrome and for those it affects, causes persistent pain and limits daily activity and work capacity. Conservative management of piriformis syndrome is advantageous with multiple therapeutic options and a substantial ability to improve pain and functional ability. Physical therapy, steroid injections, botulinum toxin injections, and dry needling are all potentially effective therapies with few adverse effects. Conservative treatment should be considered first-line for piriformis syndrome; however, minimally invasive procedures are available if treatment fails. Endoscopic decompression of the sciatic nerve with or without release of the piriformis muscle has a reported high likelihood of success and a low complication rate. Current literature supports the preference of the endoscopic approach over the open approach due to improved outcomes and decreased complications. Further research is to well define the metrics for the diagnosis of piriformis syndrome and may include a need to develop diagnostic criteria. Subsequent higher-level studies are needed to clarify the efficacy of newer therapies.

\section{Footnotes}

Authors' Contribution: Study concept and design: NV and IU. Acquisition of data: NV and IU. Analysis and Interpretation of data: NV, HK, RB, IS, EC, AK, FI, GV, MP, OV, and IU. Drafting of the Manuscript: NV, HK, RB, IS, EC, AK, FI, GV, MP, $\mathrm{OV}$, and IU. Critical revision of the manuscript for important intellectual content: NV, HK, RB, IS, EC, AK, FI, GV, MP, OV, and IU. Statistical Analysis: none; Administrative, technical, and material support: NV and IU. Study supervision: NV and IU.

Conflict of Interests: The authors report no conflicts of interest.

Funding/Support: None. 


\section{References}

1. Probst D, Stout A, Hunt D. Piriformis Syndrome: A Narrative Review of the Anatomy, Diagnosis, and Treatment. PM R. 2019;11 Suppl 1:S54-63. doi: 10.1002/pmrj.12189. [PubMed: 31102324].

2. Miller TA, White KP, Ross DC. The diagnosis and management of Piriformis Syndrome: myths and facts. Can J Neurol Sci. 2012;39(5):577-83. doi: 10.1017/s0317167100015298. [PubMed: 22931697].

3. Hicks BL, Lam JC, Varacallo M. Piriformis Syndrome. StatPearls Publishing; 2020.

4. Park JW, Lee YK, Lee YJ, Shin S, Kang Y, Koo KH. Deep gluteal syndrome as a cause of posterior hip pain and sciatica-like pain. Bone Joint J. 2020;102-B(5):556-67. doi: 10.1302/0301-620X.102B5.BJJ-2019-1212.R1. [PubMed: 32349600].

5. Siddiq MAB. Piriformis Syndrome and Wallet Neuritis: Are They the Same? Cureus. 2018;10(5). e2606. doi: 10.7759/cureus.2606. [PubMed: 30013870]. [PubMed Central: PMC6039217].

6. Keskula DR, Tamburello M. Conservative management of piriformis syndrome. JAthl Train.1992;27(2):102-10. [PubMed: 16558144]. [PubMed Central: PMC1317145].

7. Beauchesne RP, Schutzer SF. Myositis ossificans of the piriformis muscle: an unusual cause of piriformis syndrome. A case report. J Bone Joint Surg Am. 1997;79(6):906-10. doi: 10.2106/00004623-19970600000016. [PubMed: 9199390].

8. Boyajian-O'Neill LA, McClain RL, Coleman MK, Thomas PP. Diagnosis and management of piriformis syndrome: an osteopathic approach. J Am Osteopath Assoc. 2008;108(11):657-64. doi: 10.7556/jaoa.2008.108.11.657. [PubMed:19011229].

9. Jankovic D, Peng P, van Zundert A. Brief review: piriformis syndrome: etiology, diagnosis, and management. Can J Anaesth. 2013;60(10):1003-12. doi: 10.1007/s12630-013-0009-5. [PubMed: 23893704].

10. Robinson LR. Is the FAIR-test a fair method of detecting piriformis syndrome? Muscle Nerve. 2019;60(3). E20. doi: 10.1002/mus.26634. [PubMed: 31298740].

11. Wu YY, Guo XY, Chen K, He FD, Quan JR. Feasibility and Reliability of an Ultrasound Examination to Diagnose Piriformis Syndrome. World Neurosurg. 2020;134:e1085-92. doi: 10.1016/j.wneu.2019.11.098. [PubMed: 31778837].

12. Zhang W, Luo F, Sun H, Ding H. Ultrasound appears to be a reliable technique for the diagnosis of piriformis syndrome. Muscle Nerve. 2019;59(4):411-6. doi: 10.1002/mus.26418. [PubMed: 30663080]. [PubMed Central: PMC6594076].

13. Singh U, Meena R, Singh CA, Singh AKJ, Singh AM, Langshong R. Prevalence of piriformis syndrome among the cases of low back/buttock pain with sciatica: A prospective study. J Med Soc. 2013;27(2):94-9. doi: 10.4103/0972-4958.121573.

14. Cassidy L, Walters A, Bubb K, Shoja MM, Tubbs RS, Loukas M. Piriformis syndrome: implications of anatomical variations, diagnostic techniques, and treatment options. Surg Radiol Anat. 2012;34(6):479-86. doi: 10.1007/s00276-012-0940-0. [PubMed: 22327640].

15. Smoll NR. Variations of the piriformis and sciatic nerve with clinical consequence: a review. Clin Anat. 2010;23(1):8-17. doi: 10.1002/ca.20893. [PubMed: 19998490].

16. Vassalou EE, Katonis P, Karantanas AH. Piriformis muscle syndrome: A cross-sectional imaging study in 116 patients and evaluation of therapeutic outcome. Eur Radiol. 2018;28(2):447-58. doi: 10.1007/s00330017-4982-x. [PubMed: 28786005].

17. Shmagel A, Foley R, Ibrahim H. Epidemiology of Chronic Low Back Pain in US Adults: Data From the 2009-2010 National Health and Nutrition Examination Survey. Arthritis Care Res (Hoboken). 2016;68(11):1688-94. doi: 10.1002/acr.22890. [PubMed: 26991822]. [PubMed Central: PMC5027174].

18. Kean Chen C, Nizar AJ. Prevalence of piriformis syndrome in chronic low back pain patients. A clinical diagnosis with modified FAIR test. Pain Pract. 2013;13(4):276-81. doi: 10.1111/j.1533-2500.2012.00585.x. [PubMed: 22863240].

19. Cass SP. Piriformis syndrome: a cause of nondiscogenic sciatica. Curr Sports Med Rep. 2015;14(1):41-4. doi: 10.1249/JSR.0000000000000110. [PubMed: 25574881].

20. Solomon LB, Lee YC, Callary SA, Beck M, Howie DW. Anatomy of piriformis, obturator internus and obturator externus: implications for the posterior surgical approach to the hip. J Bone Joint Surg Br. 2010;92(9):1317-24. doi: 10.1302/0301-620X.92B9.23893. [PubMed: 20798456].

21. DiGiovanna EL, Schiowitz S, Dowling DJ. An Osteopathic Approach to Diagnosis and treatment. Philadelphia: Lippincott Williams \& Wilkins; 2005.

22. Divizia M, Germani G, Urti I, Imani F, Varrassi G, Meloncelli S. Endoscopic Neuromodulation of Suprascapular Nerve in Chronic Shoulder Pain: A Case Report. Anesth Pain Med. 2020;10(2). e103624. doi: 10.5812/aapm.103624. [PubMed: 32754436]. [PubMed Central: PMC7352948].

23. Huang ZF, Yang DS, Shi ZJ, Xiao J. [Pathogenesis of piriformis syndrome: a magnetic resonance imaging-based comparison study]. Zhonghua Yi Xue Za Zhi. 2018;98(1):42-5. Chinese. doi: 10.3760/cma.j.issn.0376-2491.2018.01.009. [PubMed: 29343028].

24. Heiderscheit B, McClinton S. Evaluation and Management of Hip and Pelvis Injuries. Phys Med Rehabil Clin N Am. 2016;27(1):1-29. doi: 10.1016/j.pmr.2015.08.003. [PubMed: 26616175].

25. Huang ZF, Lin BQ, Torsha TT, Dilshad S, Yang DS, Xiao J. Effect of Mannitol plus Vitamins B in the management of patients with piriformis syndrome. J Back Musculoskelet Rehabil. 2019;32(2):329-37. doi: 10.3233/BMR-170983. [PubMed: 30412481].

26. Gulledge BM, Marcellin-Little DJ, Levine D, Tillman L, Harrysson OL, Osborne JA, et al. Comparison of two stretching methods and optimization of stretching protocol for the piriformis muscle. Med Eng Phys. 2014;36(2):212-8. doi: 10.1016/j.medengphy.2013.10.016. [PubMed: 24262799].

27. Sluijter ME, Imani F. Evolution and mode of action of pulsed radiofrequency. Anesth Pain Med. 2013;2(4):139-41. doi: 10.5812/aapm.10213. [PubMed: 24223349]. [PubMed Central: PMC3821144].

28. Cox J, Varatharajan S, Cote P, Optima C. Effectiveness of Acupuncture Therapies to Manage Musculoskeletal Disorders of the Extremities: A Systematic Review. J Orthop Sports Phys Ther. 2016;46(6):409-29. doi: 10.2519/jospt.2016.6270. [PubMed: 27117725].

29. Fusco P, Di Carlo S, Scimia P, Degan G, Petrucci E, Marinangeli F. Ultrasound-guided Dry Needling Treatment of Myofascial Trigger Points for Piriformis Syndrome Management: A Case Series. J Chiropr Med. 2018;17(3):198-200. doi: 10.1016/j.jcm.2018.04.002. [PubMed: 30228811]. [PubMed Central: PMC6141415]

30. Tabatabaiee A, Takamjani IE, Sarrafzadeh J, Salehi R, Ahmadi M. Ultrasound-guided dry needling decreases pain in patients with piriformis syndrome. Muscle Nerve. 2019;60(5):558-65. doi: 10.1002/mus.26671. [PubMed: 31415092].

31. Tully J, Jung JW, Patel A, Tukan A, Kandula S, Doan A, et al. Utilization of Intravenous Lidocaine Infusion for the Treatment of Refractory Chronic Pain. Anesth Pain Med. 2021;10(6). e112290. doi: 10.5812/aapm.112290.

32. Nazlikul H, Ural FG, Ozturk GT, Ozturk ADT. Evaluation of neural therapy effect in patients with piriformis syndrome. J Back Musculoskelet Rehabil. 2018;31(6):1105-10. doi:10.3233/BMR-170980. [PubMed: 30010101].

33. Patel VB, Wasserman R, Imani F. Interventional Therapies for Chronic Low Back Pain: A Focused Review (Efficacy and Outcomes). Anesth Pain Med. 2015;5(4). e29716. doi: 10.5812/aapm.29716. [PubMed: 26484298]. [PubMed Central: PMC4604560].

34. Vij N, Traube B, Bisht R, Singleton I, Cornett EM, Kaye AD, et al. An Update on Treatment Modalities for Ulnar Nerve Entrapment: A Literature Review. Anesth Pain Med. 2020;10(6). e112070. doi: 10.5812/aapm.112070. 
35. Terlemez R, Ercalik T. Effect of piriformis injection on neuropathic pain. Agri. 2019;31(4):178-82. doi: 10.14744/agri.2019.34735. [PubMed: 31741344].

36. Rosales J, Garcia N, Rafols C, Perez M, Verdugo MA. Perisciatic Ultrasound-Guided Infiltration for Treatment of Deep Gluteal Syndrome: Description of Technique and Preliminary Results. J Ultrasound Med. 2015;34(11):2093-7. doi: 10.7863/ultra.14.12030. [PubMed: 26446817].

37. Misirlioglu TO, Akgun K, Palamar D, Erden MG, Erbilir T. Piriformis syndrome: comparison of the effectiveness of local anesthetic and corticosteroid injections: a double-blinded, randomized controlled study. Pain Physician. 2015;18(2):163-71. [PubMed: 25794202].

38. Payne JM. Ultrasound-Guided Hip Procedures. Phys Med Rehabil Clin N Am. 2016;27(3):607-29. doi: 10.1016/j.pmr.2016.04.004. [PubMed: 27468669].

39. Fowler IM, Tucker AA, Weimerskirch BP, Moran TJ, Mendez RJ. A randomized comparison of the efficacy of 2 techniques for piriformis muscle injection: ultrasound-guided versus nerve stimulator with fluoroscopic guidance. Reg Anesth Pain Med. 2014;39(2):126-32. doi: 10.1097/AAP.0000000000000056. [PubMed: 24509422].

40. Burke CJ, Walter WR, Adler RS. Targeted Ultrasound-Guided Perineural Hydrodissection of the Sciatic Nerve for the Treatment of Piriformis Syndrome. Ultrasound Q. 2019;35(2):125-9. doi: 10.1097/RUQ.0000000000000360. [PubMed: 29727344].

41. Safarpour Y, Jabbari B. Botulinum toxin treatment of pain syndromes -an evidence based review. Toxicon. 2018;147:120-8. doi: 10.1016/j.toxicon.2018.01.017. [PubMed: 29409817].

42. Fritz J, Chhabra A, Wang KC, Carrino JA. Magnetic resonance neurography-guided nerve blocks for the diagnosis and treatment of chronic pelvic pain syndrome. Neuroimaging Clin N Am. 2014;24(1):211-34. doi:10.1016/j.nic.2013.03.028. [PubMed: 24210321].

43. Santamato A, Micello MF, Valeno G, Beatrice R, Cinone N, Baricich A, et al. Ultrasound-Guided Injection of Botulinum Toxin Type A for Piriformis Muscle Syndrome: A Case Report and Review of the Literature. Toxins (Basel). 2015;7(8):3045-56. doi: 10.3390/toxins7083045. [PubMed: 26266421]. [PubMed Central: PMC4549739].

44. Rawicki B, Sheean G, Fung VS, Goldsmith S, Morgan C, Novak I, et al. Botulinum toxin assessment, intervention and aftercare for paediatric and adult niche indications including pain: international consensus statement. Eur J Neurol. 2010;17 Suppl 2:122-34. doi: 10.1111/j.1468-1331.2010.03132.x. [PubMed: 20633183].

45. Fabregat G, Rosello M, Asensio-Samper JM, Villaneuva-Perez VL, Martinez-Sanjuan V, De Andres J, et al. Computer-tomographic verification of ultrasound-guided piriformis muscle injection: a feasibility study. Pain Physician. 2014;17(6):507-13. [PubMed: 25415775].

46. Koh E, Webster D, Boyle J. Case report and review of the potential role of the Type A piriformis muscle in dynamic sciatic nerve entrapment variant of piriformis syndrome. Surg Radiol Anat. 2020;42(10):1237-42. doi: 10.1007/s00276-020-02440-8. [PubMed:32112284].

47. Fishman LM, Wilkins AN, Rosner B. Electrophysiologically identified piriformis syndrome is successfully treated with incobotulinum toxin a and physical therapy. Muscle Nerve. 2017;56(2):258-63. doi: 10.1002/mus.25504. [PubMed: 27935076].

48. Al-Al-Shaikh M, Michel F, Parratte B, Kastler B, Vidal C, Aubry S. An MRI evaluation of changes in piriformis muscle morphology induced by botulinum toxin injections in the treatment of piriformis syndrome. Diagn Interv Imaging. 2015;96(1):37-43. doi: 10.1016/j.diii.2014.02.015. [PubMed: 24703886].
49. Rodriguez-Pinero M, Vidal Vargas V, Jimenez Sarmiento AS. Long Term Efficacy of Ultrasound-Guided Injection of IncobotulinumtoxinA in Piriformis Syndrome. Pain Med. 2018;19(2):408-11. doi 10.1093/pm/pnx135. [PubMed: 28633454].

50. Ripellino P, Cianfoni A, Izzo MGA, Gobbi C. Relapsing piriformis syndrome treated with botulinum toxin injections. BMJ Case Rep 2019;12(8). doi: 10.1136/bcr-2019-230981. [PubMed: 31401586]. [PubMed Central: PMC6700580].

51. Kay J, de Sa D, Morrison L, Fejtek E, Simunovic N, Martin HD, et al. Surgical Management of Deep Gluteal Syndrome Causing Sciatic Nerve Entrapment: A Systematic Review. Arthroscopy. 2017;33(12):2263-2278 e1. doi: 10.1016/j.arthro.2017.06.041. [PubMed: 28866346].

52. Han SK, Kim YS, Kim TH, Kang SH. Surgical Treatment of Piriformis Syndrome. Clin Orthop Surg. 2017;9(2):136-44. doi: 10.4055/cios.2017.9.2.136. [PubMed: 28567214]. [PubMed Central: PMC5435650].

53. Malik KM, Imani F, Beckerly R, Chovatiya R. Risk of Opioid Use Disorder from Exposure to Opioids in the Perioperative Period: A Systematic Review. Anesth Pain Med. 2020;10(1). e101339. doi: 10.5812/aapm.101339. [PubMed: 32337175]. [PubMed Central: PMC7158240].

54. Imani F, Varrassi G. Ketamine as Adjuvant for Acute Pain Management. Anesth Pain Med. 2019;9(6). e100178. doi: 10.5812/aapm.100178. [PubMed: 32280623]. [PubMed Central: PMC7119219].

55. Jackson TJ. Endoscopic Sciatic Nerve Decompression in the Prone Position-An Ischial-Based Approach. Arthrosc Tech. 2016;5(3):e637-42. doi: 10.1016/j.eats.2016.02.020. [PubMed: 27656390]. [PubMed Central: PMC5021545]

56. Orhurhu V, Orman S, Peck J, Urits I, Orhurhu MS, Jones MR, et al. Carpal Tunnel Release Surgery- A Systematic Review of Open and Endoscopic Approaches. Anesth Pain Med. 2020;10(6). e112291. doi 10.5812/aapm.112291.

57. Ilizaliturri VJ, Arriaga R, Villalobos FE, Suarez-Ahedo C. Endoscopic release of the piriformis tendon and sciatic nerve exploration. $J$ Hip Preserv Surg. 2018;5(3):301-6. doi: 10.1093/jhps/hny018. [PubMed: 30393558]. [PubMed Central: PMC6206698].

58. Byrd JW. Disorders of the Peritrochanteric and Deep Gluteal Space: New Frontiers for Arthroscopy. Sports Med Arthrosc Rev. 2015;23(4):22131. doi: 10.1097/JSA.0000000000000085. [PubMed: 26524558].

59. Park MS, Jeong SY, Yoon SJ. Endoscopic Sciatic Nerve Decompression After Fracture or Reconstructive Surgery of the Acetabulum in Comparison With Endoscopic Treatments in Idiopathic Deep Gluteal Syndrome. Clin J Sport Med. 2019;29(3):203-8. doi: 10.1097/JSM.0000000000000504. [PubMed: 31033613].

60. Ham DH, Chung WC, Jung DU. Effectiveness of Endoscopic Sciatic Nerve Decompression for the Treatment of Deep Gluteal Syndrome. Hip Pelvis. 2018;30(1):29-36. doi: 10.5371/hp.2018.30.1.29. [PubMed: 29564295]. [PubMed Central: PMC5861023]

61. Coulomb R, Khelifi A, Bertrand M, Mares O, May O, Marchand $\mathrm{P}$, et al. Does endoscopic piriformis tenotomy provide safe and complete tendon release? A cadaver study. Orthop Traumatol Surg Res. 2018;104(8):1193-7. doi: 10.1016/j.otsr.2018.02.018. [PubMed: 29852320].

62. Aguilera-Bohorquez B, Cardozo O, Brugiatti M, Cantor E, Valdivia N. Endoscopic treatment of sciatic nerve entrapment in deep gluteal syndrome: Clinical results. Rev Esp Cir Ortop Traumatol.2018;62(5):3227. doi: 10.1016/j.recot.2018.03.004. [PubMed: 29807785]. 